\title{
Supporting Psychosocial Processes towards a Sustainable Energy System: The Case of $\mathrm{CO}_{2}$ Geological Storage
}

\author{
Samuela Vercelli \\ University of Rome "La Sapienza"- CERI \\ Italy
}

\section{Introduction}

\section{Technology and society: what are the keys to thinking and feeling?}

When we think about sustainable energy... what do we think? Do we think it is possible...or impossible? Can it be done now, or is it for the future? How can we bring it about? Is it a dream, or is it really feasible? Is there anything I can do? What can I do? It's up to industry, it's up to politicians, it's up to environmentalists... The list continues with many other examples of thoughts and feelings which might emerge when we turn our minds to the topic of sustainable energy. These thoughts and feelings will be crucial in moulding our relationship with environmentally friendly ways to produce energy. New inventions and possible solutions and choices will have to come to terms with what is in the minds and hearts of people. Producing a scientific understanding of people's thoughts and feelings can thus support the implementation of new technological solutions and ultimately our ability to develop a more sustainable energy system. From this perspective, psychosocial change processes need just as much attention and care as technological development processes, otherwise the gap between technology and society could hamper the exploitation of available technologies and solutions. This is quite an innovative approach, since the relevance of people's thoughts and feelings usually comes to the fore only when troubles arise, such as so-called "public acceptance" issues. The idea that, if we really want a sustainable energy system, we need to work on our thoughts and feelings and thus stimulate the sharing of new visions and perspectives, is not common. There are a number of activities which are conducted on a social level to facilitate the adoption of new technologies or to improve the way society reaches consensus over critical environmental decisions (Flynn \& Bellaby, 2007). But it is mostly an effort to formulate appropriate policies that can be implemented without too much resistance, or an effort to engage in effective public communication. Also, the so-called participative processes often pertain more to the realm of negotiation than to the acquisition of new common perspectives. Work on thoughts and feelings, which find expression both at individual and collective levels, can instead contribute to the co-creation of meaning, which in turn facilitates decision making both at the individual and social level. This approach to social processes is still to be discovered but we already know that it can affect ongoing change in society: first of all empowering people to direct that change; secondly, allowing the development of new shared representations (Carli, 1972; Carli \& Paniccia, 1981; Carli \& Paniccia, 2002). 
But what are the keys to thoughts and feelings? How can we gain understanding of energy issues by studying them? Here we will propose some experiences which might shed a light on possible pathways forward. Our approach recognises first of all the need to provide conditions that allow their expression. Secondly the importance of the presence of someone who is there to listen to them and who gives start to an elaboration process which can bring new insights and stimulate other thoughts and feelings and so on. Thus, in the long jouney towards a sustainable energy system, social processes, which also involve changing choices and habits require study and attention. In this context the dynamics of knowledge management and dissemination and the related issue of knowledge and technology awareness are of particular interest. Scientific and technological developments can reach the stage of exploitation only when they find full support at a social level. Studying and facilitating the emergence of the meaningfulness of specialized knowledge in our society can be crucial. What is really being done? What is its importance for society? How can this technology contribute to our quality of life? The answers to these questions cannot be taken for granted, they will be formed via an ongoing interaction within our society at all levels. How can we help this interaction? What occurs in our society that allows for a better understanding of a new technology, of how we can decide whether to deploy it or not, to support or reject it? Here we will relate some experiences in the field of $\mathrm{CO}_{2}$ Geological Storage (CGS) on how these processes can be approached and possibly facilitated.

\section{A technology to be discovered}

\subsection{What is carbon capture and storage}

The $\mathrm{CO}_{2}$ emitted when burning fossil fuels in power plants and heavy industry can be captured and stored back in the underground. We call this technology Carbon Capture and Storage (CCS).

CCS is considered one of the technologies with the biggest potential for the reduction of greenhouse gases and in particular for the abatement of $\mathrm{CO}_{2}$ emissions (IPCC, 2005; Stangeland, 2007; IEAGHG, 2008).

\subsection{CCS is mostly unknown}

Nevertheless, such an important technology is still mostly unknown to the wider public (Eurobarometer, 2006; Reiner et al., 2006; Ashworth et al., 2006; Ha-Duong et al., 2009); also among relevant stakeholders, such as authorities at national or local levels, or other policy makers, knowledge about the technology and awareness about its potential concerning climate change is still limited (Johnsson et al., 2010; Shackley et al., 2007; Shackley et al., 2009; Stephens et al., 2009).

\subsection{CCS communication}

Studies have been conducted to understand the public's perception of CCS and communication issues (Shackley \& Evar, 2009; Ashworth et al., 2009b; Reiner 2008; HaDuong et al., 2009) and guidelines have been prepared to support public communication of CCS projects (DOE-NETL, 2009; WRI, 2009; Desbararts et al., 2010). Still, much remains to be understood about how people will structure their own response to the challenges posed by the adoption of this new technology.

We can distinguish two main levels for further investigation: 
- $\quad$ understanding of the place CCS might take in our general culture as a climate change mitigation option, whether it will be recognized as a relevant technology and supported in its deployment

- understanding of the specific issues which might be raised in relation to specific contexts of application

It has to be said, that in the case of CCS, as it has been the case for prior technologies, social awareness of the technology is far behind technological development; for many social researchers (personal communications) it is difficult to comprehend the great delay in starting public consultation and communication, since social research and experience clearly show the high risks connected to lack of communication with the public.

\subsection{The role of education}

A specific issue for CCS is that, given the generally low level of education with regard to geology, it might be difficult for many people to get a good understanding of $\mathrm{CO}_{2}$ Geological Storage, or, given the limited knowledge on energy production processes, it might be difficult for them to comprehend the $\mathrm{CO}_{2}$ capture processes.

\subsection{The role of stakeholders}

Numerous studies have been focused on stakeholders already acquainted with the technology and on the important role they play both for the deployment of the technology and for the communication of information about the technology itself (Shackley et al., 2007; Vercelli \& Tambelli 2005; Heiskanen et al., 2007; Johnsson et. al., 2010; Terwel et al., 2009; Malone et al., 2009, 2010; Fischedick et al., 2009; Ter Mors et.al., 2009). The importance of these stakeholders cannot be underestimated, as stakeholders such as scientists and industrial operators constitute the sources of information on the technological process, while regulators and policy makers will be the sources of information on the rules for the technology's application. It will therefore be of interest to understand how they perceive and actualize their own role within the wider social context. At the same time, the impact of stakeholders' communication will vary depending on the cognitive and emotional substrate to be found in the social context. The way people will receive new information on the technology will be in relation both to the characteristics of the input and to the characteristics of people's culture and education. It thus appears useful to enquire both on stakeholders' perceptions and awareness and on the cultural representations existing in our society which could be relevant when getting acquainted with the new concept.

\subsection{The research}

Here we report on the research we have conducted to explore both the level of specialized stakeholders - a scientific community, $\mathrm{CO}_{2} \mathrm{GeoNet}$ Network of Excellence, created to integrate and develop scientific knowledge on $\mathrm{CO}_{2}$ Geological Storage - and the level of the people, with a study that look place in the primary school involving teachers, children and their families.

\section{The demand analysis approach (DAA)}

\subsection{The social researcher as the locus for incubating mutual understanding}

One of the big issues of our time is the great fragmentation of knowledge and, at the same time, the rare emergence of ideas or ideals that have the strength to bring people together. Knowledge production seems sometimes to loose touch with what really matters to people. 
It is thus critical for social science to find ways to get back in touch with the uncertainties and challenges which lay behind the complex solid structures of our society. These structures are reflected in the highly complex theoretical background of social researchers and in the major part of our work very often condemning it to social irrelevance. To reflect real life and get back to people and society we have experimented an approach which does not focus on the needs of theoretical and academic coherence and procedures, even though it relies on solid scientific foundations (mainly the psychoanalytically oriented "Demand Analysis" theory, the "Social Representations" theory and McClelland "Motivational" theory) but rather focuses on the heuristics of interactive activities carried on by the social researcher. The social researcher, in this perspective, becomes the medium where fragments of knowledge and of opinions come together, in the presence of theoretical structures, and undergo an elaboration process which will inevitably be seasoned with the spontaneous, 'here and now' life experience, feelings, thoughts and the unique perspective of the researcher herself. Valuing and focusing on the unique experience of the researcher herself we get on track to value and focus on the unique experience of each and every individual in our society and therefore we improve the possibility of reaching the experience of individuals to better understand their perceptions, their choices and their participation or resistance to processes of change, such as the one we are interested in with regard to energy production.

\subsection{Intersubjectivity and the co-creation of meaning}

In the field of psychoanalysis there has been a profound evolution which has brought us to recognise more and more the role of subjectivity and intersubjectivity in our relationship to reality and to others (Orange et al., 1997; Stolorow et al., 1987; Stolorow \& Atwood, 1992). The therapeutic relationship has come to be completely reshaped on this basis and furthermore it deals with the task of "making sense" together. Whereas more traditional forms of psychoanalysis are based on the dominant role of interpretation, which of course will be based on previously developed theoretical assumptions and on their elaboration by the psychoanalyst in relation to the present situation, more recent approaches focus on the continuous inter-subjective exchange between the therapist and the patient, who work together to find shared meanings for what they share and experience within their relationship. It is possible to note that what has become so relevant in psychoanalysis and also in many other psychotherapeutic approaches, namely subjectivity and the possibility of co-creating meaning, is also showing its importance more and more in the socio-political arena. The need to understand the richness of subjective perspectives of the multiple stakeholders on a given issue and the need to find ways to make sense of all this complexity thus providing satisfactory solutions for all, is growing fast. The Demand Analysis Approach (DAA) (Carli, 1987; Carli \& Paniccia, 2003) has been developed precisely to help establish contexts for relationships at both individual and collective levels, where subjectivity can find expression and the social process can develop to produce shared meanings. These meanings will shape in the form of social representation, a "form of knowledge that is socially processed and shared, which has a practical goal and concurs to the construction of the common reality of a social community.(...) Generally it is thought that social representations, because they are systems of interpretation that support our relationships with the world and with others, orient and organize behaviours and social communication. Similarly, they intervene in various processes, such as the diffusion and assimilation of knowledge, individual and collective development, the definition of personal and group identities, group expression and social transformation."(Jodelet, 1992). 
The DAA is interested to social change processes which can improve the well-being of individuals and communities and thus is not interested in finding general criteria or laws for human behaviour but rather in working on problems which might be present in the community; hence the focus on the "demand" coming from the community which will be the point of reference for understanding what will happen in the relationship between the community and the researcher. The Demand Analysis provides a valid framework for working on thoughts and feelings in that it is centred on the understanding of the relationship between the investigator and the investigated. This understanding, which proceeds recursively and reciprocally, is functional to the identification of relevant representations that the investigated and the investigator bring into the relationship in relation to the object or objective of the relationship itself, and finds its foundation in the elaboration of the emotional experience considered in terms of the unconscious system mode (Matte Blanco, 1981). The Demand Analysis thus offers the possibility to study the emergence of possible social representation dimensions, keeping in touch with both the individual and the social dimension of emotions, avoiding the risk of purely intellectual and detached understanding which inevitably doesn't manage to reach people.

\subsection{State of the art of CCS social research}

Studies conducted up to now have been oriented mostly to surveying public attitudes towards CCS or to engaging with the public in relation to some CCS projects (for a review see Shackley \& Evar, (2009)). Although the outcomes are fairly homogeneous, showing moderate like or dislike of the technology, it still appears quite difficult to account for the variability and in particular to understand if and how public perception might grow towards more radical positive or negative positions. Surveys and other activities such as focus groups, have been greatly conditioned by the fact that a limited or very limited number of people in our society have any knowledge about CCS. Many studies have thus enquired about informed stakeholders' opinions or perceptions or have tried to bypass scarcity of knowledge by providing prior information to the subjects involved, for example with an "informed choice questionnaire - ICQ" (De Best Waldhober et al., 2009). This has been only partly successful since the respondents' evaluation of the technology proved to be based only partially on the expert information provided. Also, the effort to identify the specific aspects of the technology, benefits and consequences etc. which could influence people's evaluation produced limited results as "none of the aspects or consequences sticks out as a major predictor of the evaluation" (De Best-Waldhober et. al., 2009, p.331). These results might not be surprising when we think that the topic has multiple binds to a number of controversial themes such as energy policy, energy production, climate change, siting of big industrial installations, the use of fossil fuels, etc. In addition, it might be argued that the current status of such issues in our culture is highly undefined, making it difficult for people to formulate coherent thoughts and for the experts to formulate appropriate questions; what seems to be missing is not the information but rather the criteria for making sense of the available information or for looking for missing information. In other terms, we could say that social representations (Moscovici, 1961, 1976; Jodelet, 1992) on these topics are still forming and that we have not yet developed a sufficiently common thought to orient us in our understanding and behaviour. Maybe this is one reason why, in the great majority of studies, the questionnaires and the other material for activities such as focus groups, have been prepared on the basis of the researchers' assumptions on what issues could be at stake based on materials provided by experts in the field. While a lot of information has thus been gathered on CCS perception by a number of stakeholders, it must be said that the way the questionnaires have been structured, the 
questions asked and the choice of the issues addressed, have provided information to the interviewees which would condition their input and limit it to the representation of the topic already given by the researchers. This way of proceeding presents some risks, with regard to the study of an area which has both new technological content and undiscovered social meaning. The way different publics and stakeholders might appropriate themselves of such a new technological concept could lie outside what the researchers might imagine or foresee on the basis of their own information and representation. In addition, it might be very difficult to understand what people are really thinking and feeling, without establishing a direct relationship with them. A direct relationship would instead allow to collect not only answers to our questions but, even more precious personal input, impressions, and spontaneous considerations which can help us get a "feel" of what's really going on and give us useful cues on which issues are in people's hearts. Therefore, in our attempt to understand what could be the way for people to relate to CCS and make sense of it, we have chosen to adopt a theoretical approach coherent with the need to set the conditions for people to express their own original perspectives, for detecting their own choice of issues and questions, reducing the influence of the researchers' structured thoughts to a minimum.

The proposed approach differs from that of the previous studies in at least three main aspects:

1. rather than starting with the social researchers choosing issues and questions, it sets the conditions for both the children and the researchers to raise their own issues and questions, in relation to learning about the topic for the children, and in relation to spreading the knowledge, for the researchers. This approach implies a trusting attitude towards whatever issues people might raise and recognizing their importance independently from the level of their specific competence

2. it values the direct relationship to the people as a fundamental tool for gaining realistic understanding of the issues at stake

3. it emphasizes the need to produce a deep understanding of what could prevent the dissemination and exploitation of available technological resources; what we mean by "deep understanding" is a holistic knowledge that guides us through the hurdles of complex socio-political contexts, when the application of well tested analytical guidelines might not suffice. This need implies remaining open and available to any emerging social meaning.

In adopting this approach we intend to favour the possibility of getting involved in the social processes which produce social representations. Thus we might identify the representational aspects that have the potential for guiding our society in making appropriate and sustainable choices.

\subsection{Providing insight}

From this perspective, it has to be considered that our objective is not to demonstrate or prove what people actually think and feel but rather to provide useful insights on how we can all advance, in our pathways towards sustainability, when we take into account our own as well as other people's thoughts and feelings.

\section{Being immersed in the social processes}

We propose reflecting on the social processes that we have studied with researchers and children and which gave us firsthand information on individual and collective thoughts and feelings that can arise when work is done on the processes of knowledge transmission. We 
will try to illustrate the journey we shared within the scientific community in relation to the challenges of creating a network capable of internal and external communication of scientific research. We will also discuss some of the adventures and data from the study in the school. Both these experiences seem to have more than a subtle link with one another and with the difficult path towards sustainability.

\subsection{CO2GeoNet - The European Network of Excellence for the Geological Storage of $\mathrm{CO} 2$}

In regards to the case of $\mathrm{CO}_{2}$ Geological Storage, our study is part of the research carried on within $\mathrm{CO}_{2} \mathrm{GeoNet}$ Network of Excellence, a European network of 13 research institutes, among which Sapienza University of Rome, which was promoted by the European Commission for the creation of a pan-European virtual lab to develop research on $\mathrm{CO}_{2}$ geological storage in an integrated manner (Czernichowski et al., 2009). The big gap between the advanced stage of scientific progress on $\mathrm{CO}_{2}$ Geological Storage and the very low awareness about it amongst the public and other stakeholders, was the starting point of the work. How could we disseminate knowledge? How could we efficiently communicate complex and highly specific geological concepts which explain the functioning of $\mathrm{CO}_{2}$ Geological Storage? Several aspects of the issue appeared relevant, some of them more difficult than others to approach methodically. The role of the scientific community in clarifying CGS, what it is about and its feasibility, was of course a fundamental one.

It is well known that although scientists hold a high level of credibility by the public, as is confirmed by surveys such as those of Eurobarometer (2006) about credible information sources on energy issues, nevertheless communication between scientists and the public is not so easy due to many factors, among which the considerable differences in language and cultural background. This situation, which is quite common in our society, indicates that the work on information itself, to be effective, needs to be part of a wider process; the need to communicate has to be understood in light of the numerous points of view and requests arising from scientists, the public or other more specialised stakeholders. Following this line of reasoning, a process was started within the network, through dedicated sessions and workshops, to understand the specific perspective of the researchers in their effort to disseminate knowledge and to facilitate the definition of what they actually wanted to disseminate.

Our work within the Network has been carried on in the area of the Spreading of Excellence activities, which comprised different forms of dissemination (training, workshops and conferences, a website, the media). The community of researchers, which was forming under the auspices of the European Commission, needed to coordinate its own development as an integrated network of scientific institutes and at the same time was invested with the task of communicating research on $\mathrm{CO}_{2}$ Geological Storage to other stakeholders and the wider public. It was a situation that was rather engaging and difficult to sort out: both the process of integration and the process of dissemination involved psycho-social dimensions about which the researchers - geologists, engineers, biologists, etc. - were mostly inexperienced and/or unaware. Our institute was then involved, thanks to the presence of social researchers in the research team, to support the performance of Spreading of Excellence activities through initiatives for raising awareness in the Network about $\mathrm{CO}_{2}$ Geological Storage communication issues. The work of raising awareness, following the Demand Analysis Approach, has been characterised by the exploration of communication needs, through the organization of facilitating situations and contexts and then by working with the researchers on what emerged. This process has been part of the life of the Network 
articulating itself complementarily with all the other activities for research, management, communication, etc.

A number of workshops and seminars have been conducted, for different levels within the organization, starting with the Management Board, then the high-level representatives in the Assembly, the network's governing body, and then more extensively for all the researchers. This first phase has subsequently given rise to a number of internal and external communication activities, which reflected a greater definition of communication objectives and the effort to dialogue and find an appropriate language for different stakeholders. Throughout this process a number of issues had to be faced and elaborated:

- $\quad$ the reasons for the existence of the Network and its objectives

- clarification of the context for the Network's operation: EC mandate, CCS community, wider social context, etc.

- clarifiying the relationship of the research work to its practical application, and for planning it in relation to society's needs and the requests of industrial operators or regulators

- defining the role of the single research disciplines in the framework of $\mathrm{CO}_{2}$ Geological Storage

- establishing the fundamental role of multidisciplinary integration since complementarity of knowledge is essential toward building a comprehensive framework for a solid scientific foundation of $\mathrm{CO}_{2}$ Storage

- consequently, establishing relevance of internal communication activities - not just the presentation of one's own work but also more interactive activities facilitating discussion and exchange

- examining specificity of external communication, developing an understanding of possible information needs of other stakeholders and developing communication skills.

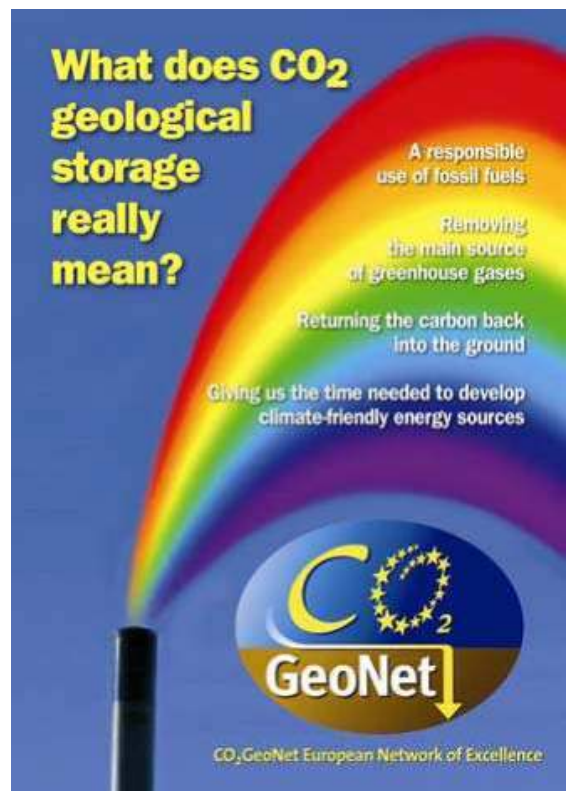

Fig. 1. Cover of $\mathrm{CO}_{2} \mathrm{GeoNet}$ brochure on $\mathrm{CO}_{2}$ geological storage 
These issues emerged gradually as the analysis of the social process developed, based on the Demand Analysis, and just as gradually, increased the awareness of the researchers about their own role beyond the production of scientific data: the need to make sense of this data, to link the data of different disciplines, and to enable accurate comprehension of the research outcomes. This implied first of all, an in-depth understanding of one another's work, thus high-intensity and high-level sharing and exchange and secondly the capacity to explain the meaning implicit in the data, which was developed through the effort to communicate externally. A number of specific activities were conceived and became the opportunity to materialize this process, or we could say, this progress. A milestone, in particular, was the Training and Dialogue Workshop on "What does $\mathrm{CO}_{2}$ Geological Storage really mean?" which took place in Paris in the Autumn 2007. The idea for this workshop, the way it was developed, the method for integration and communication of knowledge which we practiced together were the fruit of the work on social processes within the Network. They were the outward manifestation of a new awareness about the role of researchers in a wider social context, in relation to a new emerging social representation (Vercelli \& Lombardi, 2009). Further developments of the Paris workshop have led us to produce, thanks again to the coordinated efforts of a multidisciplinary team of researchers, a scientific brochure with the same title (fig. 1). This brochure is not just a comprehensive explanation of the scientific foundations of $\mathrm{CO}_{2}$ Geological Storage, it is an example of integrated knowledge production and dissemination; it is an example of how very specialized scientific research can be made available and accessible: the brochure is downloadable from $\mathrm{CO}_{2} \mathrm{GeoNet}$ website www.co2geonet.eu and is already available in 10 languages thanks to the collaboration on the translation, of a number of other entities outside the Network.

What is new and good is that the synergy between the European Commission mandate for building the Network and promoting integration, high level scientists, attention and work on social processes has given us the possibility to experiment new ways for knowledge production and dissemination. What we learned during this process is the importance of direct exchange and discussion in a safe environment.

In our case, the rise of strong personal relations and a trusting atmosphere, together with strong achievement motivation, played a central role. We will see below what we intend for achievement motivation and how it relates to the work we did with children.

\subsection{The primary school project}

The way energy issues are represented in our society will be reflected in what children learn at school and absorb from the social environment they live in. At the same time, the structuring of thoughts and cultural dimensions in children is still very plastic, children are much quicker at learning new things and usually more open and curious towards new ideas and practices. This is why we considered working with children particularly interesting for gathering information on the psycho-social challenges linked to the introduction of a new technology such as CCS. Last but not least, today's children are the adults of tomorrow: they will be the ones who will be involved in the deployment of new technologies.

\subsubsection{Contact with the children}

It is well known that we learn best when we are enjoying ourselves; also self-expression is encouraged by activities which we take pleasure in. For these reasons, because the topic we wanted to communicate about was quite technical and intellectual, we tried to communicate 
it in a simple, enjoyable and playful way. The scope was to support full learning and full self-expression and thus maximise the value of reciprocal exchange with the children. How would they learn about CCS? Would they be interested?

\subsubsection{The activities}

The study took place in three Roman primary schools and was dedicated to understanding how the children would build their own relationship to the proposed topic, how they would learn about it and interact with regard to the dynamics of problems and solutions. The study continued in the time frame of two subsequent school years. One fundamental criterion in building the context for our work with the children and the teachers, was the establishment of a collaborative and enjoyable relationship. This relationship was the main source of information for the social process that was activated during the research and for the introduction of scientific concepts. The production of materials such as drawings or written texts is part of this relationship which also accounts for their significance. Much care was thus given to avoid a frontal teaching setting and to creating as equal relationship as possible where the children could express themselves freely, wouldn't worry about making mistakes, would feel free to explore, and would ask questions and experiment. Of course this was long, and intensive task, meeting 13 classes for 7 sessions (for 2 hour sessions), plus: one "meeting a scientist" session (a dialogue setting, where a geology researcher was available to answer all sorts of questions); one visit to our Fluid Chemistry Lab (where the children were shown how we take gas samples, measure $\mathrm{CO}_{2}$, and were allowed to do some gas and water experiments themselves); a final event with the families (where the children explained to their parents and relatives what they had learned during the project with the help of posters they had previously prepared); preparatory meetings with the teachers.

\subsubsection{Questions: the relationship with the children}

When we worked with children in the classroom we were interested in observing spontaneous imagination and thought processes evoked in children on the topic of energy and pollution. It is very important from a psychological point of view, that spontaneous contents and reactions can find room for expression (so they can be observed), since they will be the real determinants for related behaviour. We had prepared the teachers to support our work, for example, accepting whatever the children said without criticism. But very often a situation would arise where the children expressed concepts, which in the eyes of the teacher, were "wrong", and so the teacher would intervene and "correct" the child. In this context it was difficult to introduce new concepts; since both the children and the teachers were very worried about what was right or wrong, and little room was left for adventuring into new areas of knowledge, for experimenting, or for asking questions... But whenever we managed to create a relaxed situation in the classroom and the teachers tolerated free selfexpression, the children would raise many questions and engage in in-depth discussions. Then the topics proposed became an opportunity for exploring and expressing all sorts of doubts and curiosities. In any case, the sessions were pleasant and lively and the children showed a lot of enthusiasm for the subject and all the activities done together. The opportunity to interact with University researchers in an open setting was perceived as precious particularly when, through play activities, we could talk and "discover" new things. The feeling was, that there was never enough time for this kind of exchanges, the ones which were more satisfactory. Just as in our work within $\mathrm{CO}_{2} \mathrm{GeoNet}$, the value of 
establishing a safe environment where everybody could feel free to express oneself emerged. This was new and good and not only the children but most of the teachers appreciated the difference in their everyday learning/teaching experience. Protecting the children from criticism and judgement wasn't easy because the teacher's themselves felt exposed to criticism and judgement when the pupils were not, in their eyes, up to the task. The understanding that the freedom to be wrong would enhance the capacity to explore, to be creative, and to find solutions, even though it was recognized, was very difficult to practice. We wonder how much of our ability to solve problems is sacrificed by the need to be right... This thought and this feeling have accompanied us all throughout the work in the schools and with it, the thought of how important it would be to free human resources to be able to stand up to issues such as those of energy and pollution. Further on this path, today we would reinforce the emphasis on creating an environment where the children could feel free to explore and set their own learning agenda. Although during the project all the contents were proposed in an interactive mode, through dialogue and experiments, and adjusted to answer the requests coming from the children, we now think that on the level of content, the process of appropriation would have been much more efficient if the children had taken the lead in the choice of topics, following their own interests. We would now try to overcome the limits created by the fact that we proposed set material, which had been decided for research reasons. It would probably have been much more efficient to work with a different approach, starting from the problem and then just supporting the children in finding information rather than providing it for them. Of course this would have been much more difficult to handle from a research point of view and in due regard to the teachers, who already found the adopted setting very innovative.

\subsubsection{The drawings}

For this publication we have taken into consideration some of the results regarding the drawings produced at the beginning and at the end of the study in year one and in year two. The children were in $4^{\text {th }}$ and $5^{\text {th }}$ grade (9-11 years old) and produced a total of 650 drawings. We asked the children to make the first drawing the very first time we met them, to survey their representation before the work to be done together started; after spending some time getting acquainted we had a short interaction connecting them to the topic of interest. We asked them if they knew what energy is, how it is produced and what are the consequences on the environment; the children were encouraged to say without any input on our part. After these questions and answers we asked them to please make a drawing on this issue and/or its possible solutions.

The second drawing was done at the end of the first year, after having introduced new concepts about geology, gas, special characteristics of $\mathrm{CO}_{2}$, energy production, the issue of greenhouse gases, and possible solutions for reducing $\mathrm{CO}_{2}$ emissions including CCS. The third drawing was done after one year, having been refreshed through dialogue and play on what had already been done together. For some examples of the drawings see figure 2, 3, 8.

\subsubsection{Drawings codification}

The drawings have been classified for a number of variables. The ones we will consider here are "Motivation need" and "Relationship to pollution".

For the "Motivation need" variable, we refer to the theory of human motivation of David McClelland, who identifies three major needs driving human behaviour: the need for 
Affiliation, when the main concern is for establishing, maintaining or restoring a positive affective relationship with another person or persons; the need for Power, which pushes people towards controlling or influencing other people's behaviour or towards influencing the environment around them and the need for Achievement, which carries out the function of guiding man's behaviour toward the search for a solution to individual and social problems. For a complete description of the three motives see McClelland (1987).

To apply McClelland motives to the drawings' codification some specific criteria have been formulated to facilitate the identification of the motivational disposition of the child in relation to the topic of the drawing (see Table 1).

\section{Need for Affiliation}

- The problem is experienced at a community level without seeking a solution

- Powerlessness regarding pollution that leads to stasis or delegation

- The problem is present, the question of whether it should be addressed is not asked, but social dimensions are recoverable, at times with negative connotations (even though the relationship can generate anxiety, it is the solution to the problem)

- Absence of attribution of cause or fault

- Presence of the problem and the active remedial action but it is tautological

\section{Need for Power}

- One is an active part in the polluting process (power over...)

- Presence of causative factors with negative effects, but in the drawing potential solutions are excluded

- Pollution controls and determines certain phenomena

- Pollution is held responsible of a (people's, animal's or other entity's) problem, pollution has the power to condition people's life

- Powerlessness. The cause (in terms of whose fault it is) is identified and no potential solutions are foreseen

- Powerlessness regarding pollution, that leads to a request for help

Need for Achievement

- Solutions are proposed

- The subject is actively engaged in the process for finding solutions

- The pollution process is described

- Presence of causes, not faults

- The process is described even if only partially. If the process is described highlighting powerlessness, it is need for power

Table 1. Criteria for the codification of "Motivation need" in the drawings

The "Relationship to pollution" variable is defined here as the emotional relationship towards the pollution issue reflected by the dominant point of view in the drawing. After an initial screening of the drawings, we have identified five criteria: 1) acting, 2) witnessing, 3) being subjected to, 4) blaming, 5) being constructive, 6) other. See table 2 for codification criteria. 


\section{Acting (code 1)}

- If the subject (in the description) pollutes or damages the environment, we consider it "acting" also if there is somebody subjected to it. If it is the main subject to be subjected, it will be classified with code 4

- It is not the subject that acts but an element of the drawing (a factory, a car, a house, etc.). The intention to pollute is expressed in the written description of the drawing

- Elements that pollute or degrade the environment are personified. If there is no personification, it will be codified as a description (code 2)

- An action that generates a negative consequence

- The form -ing is utilized to explain an action taking place. E.g. "They are polluting" is an action taking place at that moment, it is different from "pollutes": one who observes the process in a detached way (code 2)

\section{Witnessing (code 2)}

- A situation is "objectively" described, an external point of view is assumed

- A person or a personification is present that is actively polluting but it is only one of the elements in the drawing. The person and the other inanimate elements are present in the drawing with a similar function. E.g. a child that pollutes in a city with cars, factories and airplanes that pollute. The subject is in the position of the observer

- When a subject is present that pollutes and there is one who is suffering, if none of them predominates (acting or being subjected to) it is code 2

\section{Blaming (code 3$)$}

- Rules are dictated to avoid polluting behaviour, presence of punishment for the polluter

- Presence of bans in the drawing e.g. posters or warnings present in the description

\section{Being subjected to (code 4)}

- The drawing focuses on a factor that is actively polluting and a person /personification/animal that suffers the consequences

- Feeling ill due to someone / something

- Presence of animals or people that suffer the effects of pollution or damage to the environment

- Planet Earth suffers the effects of pollution or other activities that bring damage to it. Presence of elements that refer to a condition to passivity. E.g. Planet Earth cries

- Powerlessness and stasis (delegation) or request for help, not knowing what to do

- The fact that the subject is being subjected to pollution is present in the description

\section{Being constructive (code 5)}

- An active role in the process of environmental improvement. E.g. recycle, separate, turn off light

- Presence of a clear solution to pollution problems

- Proposal of solutions even if bizarre or not feasible

- The text describes what should be done to face pollution even if in the drawing it is not detectable

- Constructive elements are not present in the drawing but in the description

Other (code 6)

- Not clearly classifiable in the previous categories

Table 2. Criteria for the codification of the "Relationship to pollution" in the drawings 


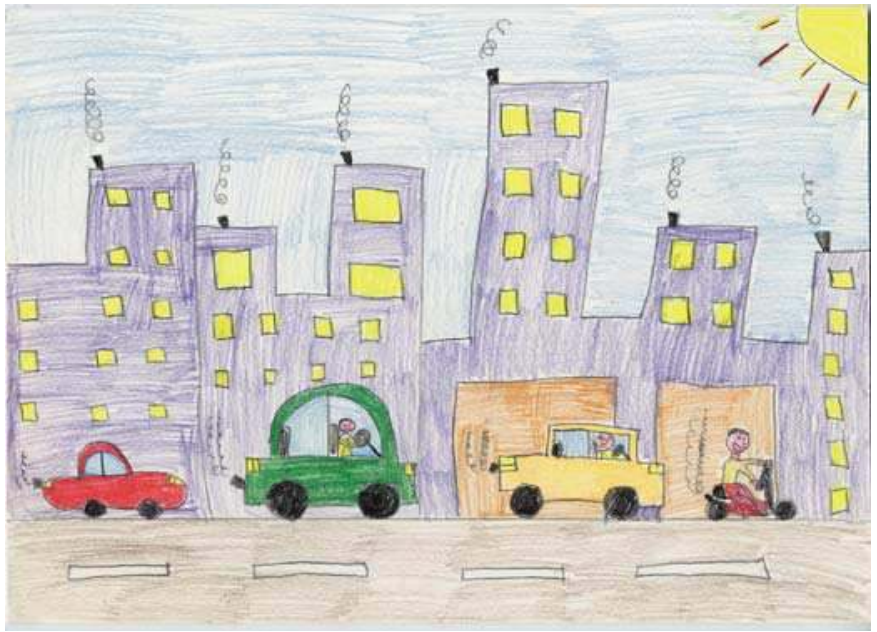

Fig. 2. "I drew polluted Rome. Air pollution" (Affiliation/Witnessing)

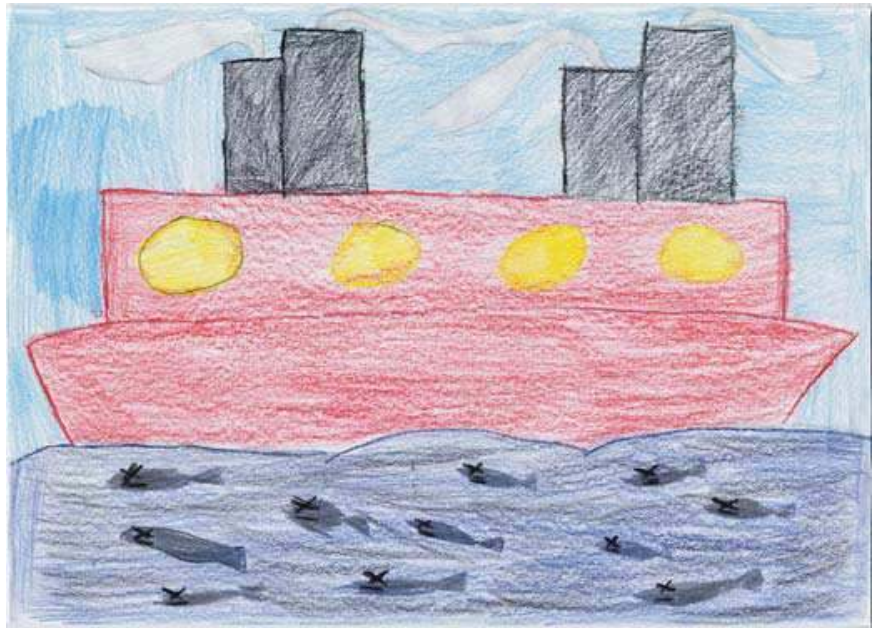

Fig. 3. "I drew an oil tanker that pollutes the sea and makes fish die" (Power/Being Sub. to)

\subsubsection{Results}

The majority of the drawings present a motivational dimension of Achievement $(55,5 \%)$, followed by Affiliation (30,8\%) and Power (13,7\%) (Table 3). Clearly, most of the children are driven to the issue of energy and pollution in terms of problems/solutions. It is interesting to note that the Achievement motive increases over time, while the Affiliation motive diminishes (Table 3, Figure 4).

When we look at the second variable (Table 4), the Relationship to pollution, we can see that the majority of children express a position of Witnessing $(51,8)$, followed by Being constructive $(18,2 \%)$, Being subjected to $(10,6 \%)$, Acting $(9,2 \%)$, Other $(7,8 \%)$ and Blaming $(2,3 \%)$. (Table 4$)$. 


\begin{tabular}{|c|c|c|c|c|c|c|c|c|}
\hline \multicolumn{10}{|c|}{ Motivation needs } \\
\hline & \multicolumn{2}{|c|}{ I drawing } & \multicolumn{2}{|c|}{ II drawing } & \multicolumn{1}{|c|}{ III drawing } & \multicolumn{2}{c|}{ Tot } \\
\cline { 2 - 10 } & $\mathrm{N}$ & $\%$ & $\mathrm{n}$ & $\%$ & $\mathrm{n}$ & $\%$ & $\mathrm{n}$ & $\%$ \\
\hline Need for Affiliation & 83 & 34,6 & 86 & 35,4 & 31 & 18,6 & 200 & 30,8 \\
\hline Need for Power & 37 & 15,4 & 34 & 14,0 & 18 & 10,8 & 89 & 13,7 \\
\hline Need for Achievement & 120 & 50,0 & 123 & 50,6 & 118 & 70,6 & 361 & 55,5 \\
\hline Total & 240 & 100 & 243 & 100 & 167 & 100 & 650 & 100 \\
\hline
\end{tabular}

Table 3. Motivation needs, evolution over time and totals

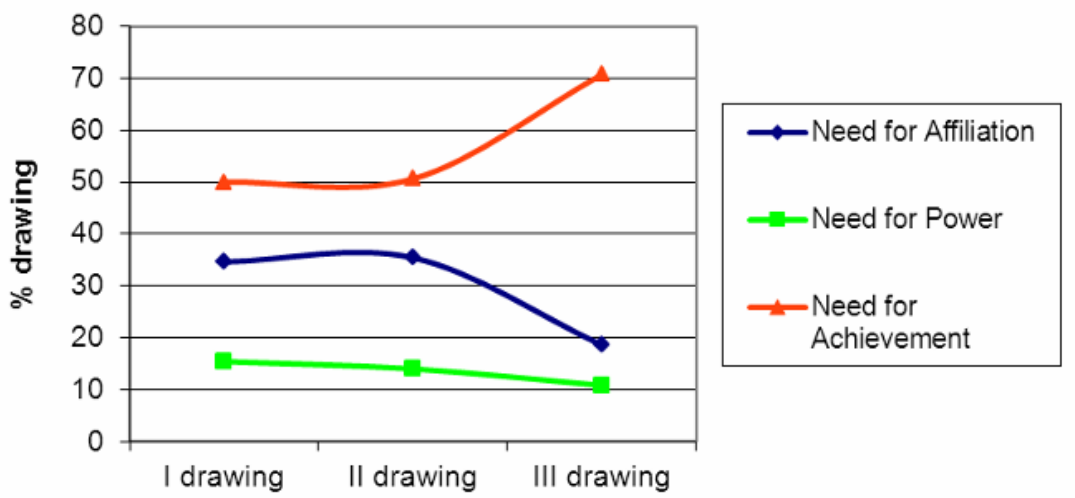

Fig. 4. Motivation needs: evolution over time

It can be noted that the high Achievement need does not correspond to a high Being constructive relationship with pollution.

If we look further in detail we can see that throughout the project Being constructive has a sharp increase, from $10,8 \%$ at the stage of the first drawing to $31,1 \%$ at the third drawing. Acting and Being subject to, show a tendency to decrease (from $11,3 \%$ to $2,4 \%$ and from $15 \%$ to $9 \%$ respectively) (Table 4 , Figure 5). This is quite comforting since the presence of a number of drawings expressing the active will to pollute was rather alarming.

If we take only the drawings which have been rated as Achievement need, we can see that in this case the number of children who express a Being constructive attitude is much higher from the beginning and further increases in time. In this group we also find lower Acting, Blaming and Being subjected to attitudes (Table 5, Figure 6).

Finally, if we compare the Relationship to pollution found in the three sub-groups, interestingly we can see that the drawings rated for Affiliation present the highest rate of Witnessing and a dominant one. The drawings rated for need for Power present high rates for Acting and Being subjected to. While the drawings categorised as Achievement present high rates of Witnessing and Being constructive (Table 6, Figure 7).

All the data are here considered as trend indicators, not for their statistical significance. 


\begin{tabular}{|c|c|c|c|c|c|c|c|c|}
\hline \multicolumn{10}{|c|}{ Relationship to pollution } \\
\hline & \multicolumn{2}{|c|}{ I drawing } & \multicolumn{2}{|c|}{ II drawing } & \multicolumn{2}{|c|}{ III drawing } & \multicolumn{2}{c|}{ Tot } \\
\cline { 2 - 10 } & $\mathrm{N}$ & $\%$ & $\mathrm{n}$ & $\%$ & $\mathrm{n}$ & $\%$ & $\mathrm{n}$ & $\%$ \\
\hline Acting & 27 & 11,3 & 29 & 11,9 & 4 & 2,4 & 60 & 9,2 \\
\hline Witnessing & 128 & 53,3 & 125 & 51,4 & 84 & 50,3 & 337 & 51,8 \\
\hline Blaming & 3 & 1,3 & 8 & 3,3 & 4 & 2,4 & 15 & 2,3 \\
\hline Being subjected to & 36 & 15,0 & 18 & 7,4 & 15 & 9,0 & 69 & 10,6 \\
\hline Being constructive & 26 & 10,8 & 40 & 16,5 & 52 & 31,1 & 118 & 18,2 \\
\hline Other & 20 & 8,3 & 23 & 9,5 & 8 & 4,8 & 51 & 7,8 \\
\hline Total & 240 & 100 & 243 & 100 & 167 & 100 & 650 & 100 \\
\hline
\end{tabular}

Table 4. Relationship to pollution over time and total

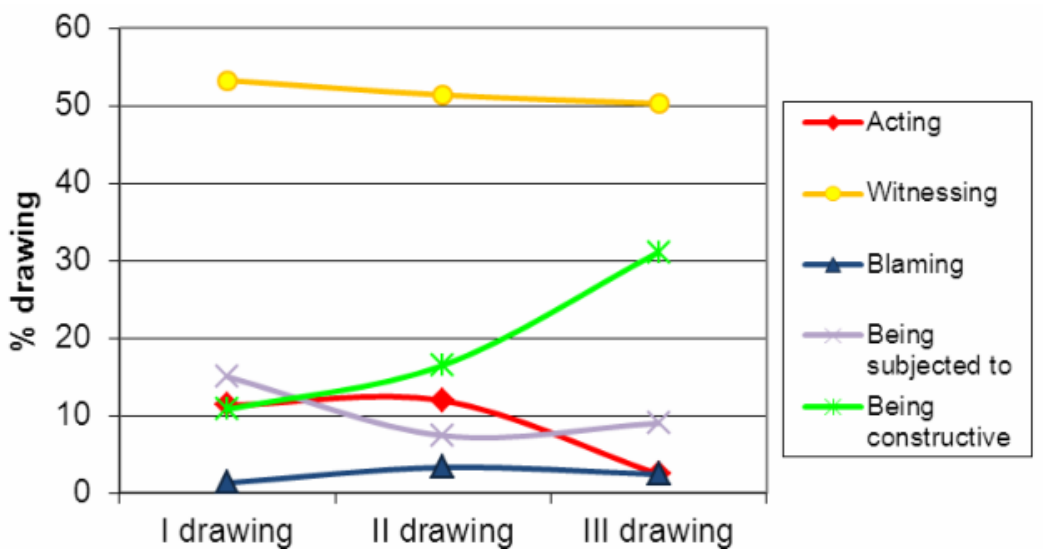

Fig. 5. Relationship to pollution over time

\begin{tabular}{|c|c|c|c|c|c|c|c|c|}
\hline \multicolumn{10}{|c|}{ Need for achievement/Relationship to pollution } \\
\hline & \multicolumn{2}{|c|}{ I drawing } & II drawing & \multicolumn{1}{|c|}{ III drawing } & \multicolumn{2}{c|}{ Tot } \\
\cline { 2 - 10 } & $\mathrm{n}$ & $\%$ & $\mathrm{n}$ & $\%$ & $\mathrm{n}$ & $\%$ & $\mathrm{n}$ & $\%$ \\
\hline Acting & 10 & 8,3 & 7 & 5,7 & 1 & 0,8 & 18 & 5,0 \\
\hline Witnessing & 72 & 60,0 & 71 & 57,7 & 63 & 53,4 & 206 & 57,1 \\
\hline Blaming & 2 & 1,7 & 2 & 1,6 & 2 & 1,7 & 6 & 1,7 \\
\hline Being subjected to & 10 & 8,3 & 4 & 3,3 & 5 & 4,2 & 19 & 5,3 \\
\hline Being constructive & 25 & 20,8 & 36 & 29,3 & 47 & 39,9 & 108 & 29,8 \\
\hline Other & 1 & 0,9 & 3 & 2,4 & - & - & 4 & 1,1 \\
\hline Total & 120 & 100 & 123 & 100 & 118 & 100 & 361 & 100 \\
\hline
\end{tabular}

Table 5. Need for Achievement/Relationship to pollution over time and totals 

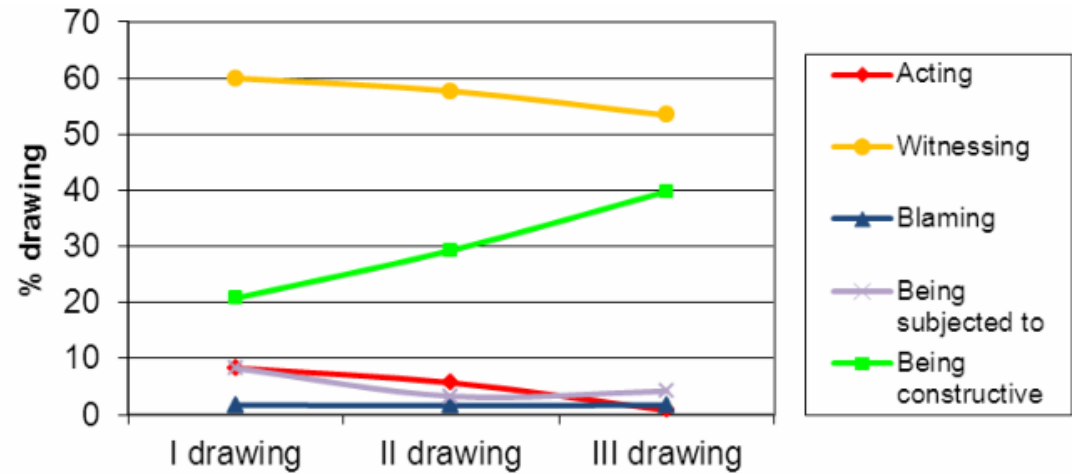

Fig. 6. Need for achievement/Relationship to pollution over time

\begin{tabular}{|c|c|c|c|c|c|c|c|}
\hline \multicolumn{7}{|c|}{ Motivation Needs/Relationship to pollution } \\
\hline & Need for Affiliation & Need for Power & Need for Achievement \\
\cline { 2 - 7 } & $\mathrm{n}$ & $\%$ & $\mathrm{n}$ & $\%$ & $\mathrm{n}$ & $\%$ \\
\hline Acting & 11 & 5,5 & 31 & 34,8 & 18 & 5,0 \\
\hline Witnessing & 119 & 59,5 & 12 & 13,5 & 206 & 57,1 \\
\hline Blaming & 6 & 3 & 3 & 3,4 & 6 & 1,7 \\
\hline Being subjected to & 12 & 6 & 38 & 42,7 & 19 & 5,3 \\
\hline Being constructive & 6 & 3 & 4 & 4,5 & 108 & 29,8 \\
\hline Other & 46 & 23 & 1 & 1,1 & 4 & 1,1 \\
\hline Total & 200 & 100 & 89 & 100 & 361 & 100 \\
\hline
\end{tabular}

Table 6. Motivation Needs/Relationship to pollution

\subsubsection{Discussion}

What appears as the most interesting result, is that the topic of energy and pollution generates Achievement motivation in the majority of the children, that is, it is seen as a problem to which a solution needs to be found. But when we look at the way the children relate to the problem, then we can see that the majority of them cannot envisage a positive and active behaviour towards the solution. Only a minority of the children can think and feel that something can be done; this group increases over time and actually triples by the end of the study. It can be observed that the increase in the "being constructive" attitude corresponds to a decrease in the "acting" and "being subjected to" categories, as if negative behaviour and/or situations could be abandoned once the possibility of constructive behaviour, through the project's experience, becomes a real option. There is, instead, only a slight shift in the number of children who look at pollution without taking any active negative or positive attitude; the "witnessing" attitude decreases, but the actual reduction is very small (Table 4 ).

But when is the "being constructive" attitude found? If we look at Table 6, we can see that when the Achievement motive is not activated, it is very unlikely that the children manifest a constructive attitude in their relationship to pollution (Table 6). This attitude is overwhelmingly linked to the Achievement motive. The importance of how to support the 


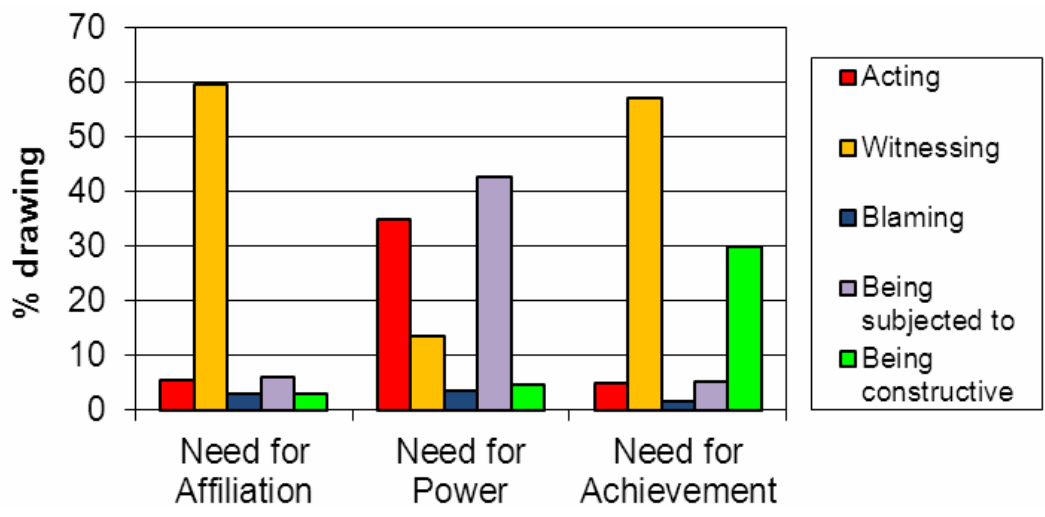

Fig. 7. Motivation Needs/Relationship to pollution (totals)

children in the development of this motivational dimension stands out. Going into further detail (Table 5), we can see that the children whose drawings were classified in the Achievement motivation category made interesting changes in the course of time: the category "Acting", which corresponds to the representation of the will to pollute, practically disappears and "Being subjected to" is halved, while being constructive nearly doubles (see also figure 6); also "Witnessing" has an interesting decrease. Nevertheless, the presence of such a high "Witnessing" percentage lends itself to speculation: why so many of the children, notwithstanding their Achievement motivation, do not express a problem solving attitude? We will not try to give an answer since more research is certainly needed here, but at least it can be pointed out that the project's activities seem to have produced a higher coherence between the Achievement need and the way the children relate to pollution. Further analysis of this data together with the data from the written texts collected will be carried out to make some hypotheses for future studies regarding which factors can be identified to explain and possibly to promote this change. Concerning future research, it would be useful to test if a similar mechanism is activated with adults, particularly when they come into contact with new technologies or solutions; is Achievement motivation as important for the adult population and can the same gap with one's own personal relationship to the problem be found? If such outcomes were obtained in a privileged context, where there was full willingness to collaborate, to learn and to get involved, what can we expect in more difficult conditions, when in addition a number of other factors, such as vested interests will be playing a role?

Another outcome that appears problematic, is that for all the children who fall within the two other motivation categories, Affiliation and Power, the access to a constructive attitude is very restricted (Figure 7, Table 6). The attitude of children classified for Affiliation is overwhelmingly passive rather than active, and the opposite can be found when Power motivation is present. In this case, though, it is only rarely a positive kind of action: the children classified as Power seem to be trapped between two negative sorts of relationships with pollution: either actively polluting or being subjected to pollution. Again, it would be interesting to understand if these results would also be indicative for the adult population. These data, especially the ones relating to the Power motive might be related to a problem that arises regularly when issues about the introduction of new technologies are discussed, the idea that there will be people who will be opposed in any case, independently from any reasonable argument. We got the same feeling in the classroom, when sometimes a child 
would ask for explanations and then would refuse them, as though we had entered a dimension of "trying to convince". Looking at these data, the hypothesis can be made that when such a situation occurs, we are in the presence of a problem which is not being approached with a problem-solving attitude because those involved get trapped in the dynamic of a Power motive, which does not allow reciprocal listening and understanding, which the Achievement motive would instead support. The "profoundly perceived trust in one's ability to accomplish" (Carli, 1972) which is characteristic of the Achievement motivation would probably support a more trusting relationship to the other and its reasons. If this were the case new, interesting considerations could be investigated to support the development of such difficult situations.

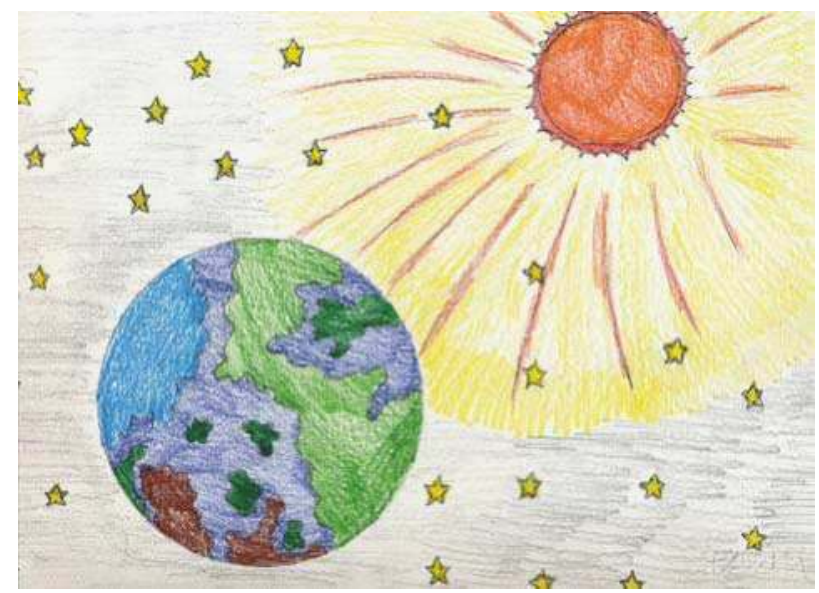

Fig. 8. "I drew the greenhouse effect: the sun illuminates and warms the earth with its rays. Carbon dioxide is represented in grey and lots of stars. The sun's rays go into the earth but can't get out and so the greenhouse effect is created."

We will now take into consideration these data and draw them together, as they build a comprehensive picture and reflect on the possible social representation of the issues related to energy production and pollution. We can see, first of all, that the major trend to be found corresponds to not feeling actively involved or interested (high "Witnessing" score in all the sample) while in the same time there are others who create the problem ("Acting") or are victimised of it ("Being subjected to") or are trying to find solutions ("Being constructive"). In other words, the direct and practical relationship of these issues with the life of each and every one is not obvious. So, the idea is, that we have a problem, which we can somehow deal with (dominance of the Achievement motive), but it is unclear who and how, it can be solved.

When we consider change processes, we see that at the end of the project the predominance of the Achievement motive $(70 \%$, Table 3 Figure 4$)$ goes together with the increase of the Being constructive attitude (31,1\%, Table 4, Figure 5). At the same time the increase of the Achievement motivation goes together with the decrease of the Affiliation motive while the Power motive is reduced but rather stable. This last data seems to reinforce the impression that the shift towards a more realistic representation of the issues at stake will take advantage of a perspective where energy, pollution and the deployment of new technologies can be seen as a problem to which everyone can give a contribution. This aspect was greatly 
emphasized in the work with the children and the children gave us researchers a great contribution to understanding dissemination and communication issues about the technology and also a more comprehensive view of the problems linked to energy production. Our thoughts on CCS were completely transformed after the experience in the school, for example it was of great help in integrating our views on geological storage, which we were specialized in, along with all the other aspects of the technology, of energy production, etc. At the end of the project we can predict a different social representation, where the weight of Witnessing becomes less important as Being constructive is much more present and thus the motivation to Achieve is more solidly experimented.

\section{General discussion}

The data regarding the drawings match our experience with the teachers and in the classroom. Just as we found high Achievement motivation and low Being constructive rate in the drawings, we found high willingness to collaborate but a lot of limitations and powerlessness when proposing collaborative approaches to learning and when exploring new concepts. Very often, it is as though the teachers or the children would like to do it differently or to explore new paths, but don't know they can, or consider some of the possible pathways to be "wrong". We have met the same kind of difficulties when working with the researchers. It is possible to say that they also presented a high Achievement motivation, but when it came to making sense of their experience or communicating it to the outside world, their awareness about their potential and about possible ways for being constructive was low. In both cases work on the social process, following the Demand Analysis Approach and thus bringing attention to subjectivity, giving respect and listening before proceeding to subsequent interpretative actions, which could support the ongoing social processes in relation to the respective objectives, produced interesting changes. While $\mathrm{CO}_{2} \mathrm{GeoNet}$ research community found the way to a number of satisfactory communication actions, children and teachers started to enjoy the work on difficult scientific topics, made new experiences and discovered they were important, just as the scientists, for solving energy problems. Particularly interesting, from this point of view, was the final activity held with the participation of the children's families where the children became their parents' teachers, explaining to them what they had experienced and learned during the project. We remember how exciting and moving these moments were, not only for the children but for all of us involved, and how meaningful it was to see the children take courage and explain difficult issues and terms.

So, this appears as the first part of the problem, raising awareness of what each and everyone can do and setting the conditions for free experimentation, so that people can find out if certain paths are "really" wrong. Freedom to experiment means more tolerance for mistakes and allowing more time to discover, that is, lower efficiency expectations. Just one example: it was very hard and it took a considerable amount of time and patience to introduce interactive communication activities in the research community meetings and conferences. Although each time this was done these activities would prove more and more productive and satisfactory, nevertheless a lot of experimenting was necessary to overcome the idea that it was just a "waste of time" or that it was not appropriate to the context, etc. In the same way, it was not easy to get the support of the teachers for letting the children express "wrong" thoughts or ideas without immediately correcting them.

Awareness grew in a context of a trusting environment and trust appears in fact as another important part of the problem, one which certainly needs more research. In this respect, 
both experiences show the relevance for the subjects of having a direct experience of the effects of a trusting relationship and of a supportive environment: this definitely seems to have a very positive impact. An aspect that needs more investigation are the conditions and the institutional, organizational arrangements, outside of experimental research conditions such as the ones we have experienced, that could support the creation of trusting environments which can favour the development of the Achievement motivation and its practical application. It would certainly be a major accomplishment to identify such organizational conditions, since, as Carli well explains: "Cooperation, in fact, more than the result of (a difficult) generic voluntarism, appears rather like the result of an automation of the need for achievement, of a profoundly perceived trust in one's ability to accomplish, and therefore an action that takes place on the basis of an elevated probability of success."(Carli, 1972).

Paradoxically, to develop such trust we need a trusting environment where we are not concerned about making mistakes. In fact, the biggest problem encountered in creating the conditions for the work on the social process was overcoming everybody's needs to protect themselves from criticism, because criticism would be destructive. This remains a major challenge to be overcome, making confrontation accessible, which in turn is useful for solving problems.

Another aspect that seems part of the social representations that condition our perception of energy issues is the idea that we should not take pleasure in what we do: enjoying ourselves when working or studying is seen just as a possible "plus" to what we do, not as an important requirement. This aspect seemed to account for some portion, for example, of the relatively low Being constructive rate in the drawings; sometimes the children seemed to find it very hard to engage the process of problem-solving, but this was not surprising if we considered that the teachers would try to make something "serious" out of what was done, or were too concentrated on final results and not interested in the process of getting there. This is also a conspicuous problem in the research community, where the pressure for efficiency and good use of time, for example in the organization of meetings, doesn't leave much room for a more pleasurable dimension which would probably foster more creativity and increase the ability to reach substantial results. This is especially true in the CCS community, where the feeling of urgency and magnitude of the problems to be solved is very high: the impending climate change challenge and the large scale of the possible solutions make it difficult for people to keep in touch with the overall process with a real feeling of competency and achievement.

\section{Conclusions}

The research performed on social processes within the framework of the Demand Analysis Approach has produced some interesting insights on the social issues that might condition the introduction of new energy technologies and particularly CCS:

1. The first area of interest that emerged concerns the opportunities of appropriate contexts and conditions for exchange and discussion. Both in the case of the scientific community and in the case of school children, what seemed to be most problematic was the lack of time and situations for sharing, for discussion and having time to think about problems within a trusting social environment. This is quite understandable if we think of the complexity of energy issues, of how difficult it is for people to orient themselves on these problems and to the fact that in order to face them, everyone's contribution not just that of specialized stakeholders, is essential. It will be useful to 
consider that, although we apparently live in a world where communication is intense and simple, the opportunities for people to meet and take time to discuss issues of common interest have become greatly reduced. So this might be the case, but only one aspect of it. Another aspect is the competence needed to make these exchanges profitable: what emerges from the study indicates the need to develop both personal skills and social structures that can facilitate these exchanges.

2. The second area concerns the representation of the energy issue in terms of "a problem to be solved". The high presence in the school sample of the Achievement motive (and the high motivation to Achieve found in the research community) give us interesting information on the direction psycho-social processes can take when appropriately supported. Diffused and competent exchange activities of people driven by the Achievement motive could probably accelerate progress towards sustainability. What is critical though, is the gap between the frequency of the Achievement motive and the representation of oneself as a positive actor; this aspect needs to be better understood. Both the experience in the school and with researchers seem to point to the importance of specific social experiences that enable the subjects to relate personally in a more satisfactory (meaningful and practical) way to the energy or technology issue. Nevertheless it will be interesting to see the results that emerge from the written texts collected in the school, as to whether there are factors specific to the energy theme which influence the low Being constructive rate or if it is a more general factor of social competence that is influential.

3. The experience within $\mathrm{CO}_{2} \mathrm{GeoNet}$ Network of Excellence indicates that $\mathrm{CO}_{2}$ Geological Storage communication issues are strongly related to the quantity and the quality of the work necessary to produce effective scientific information material and events. In addition to the specific characteristics of the topic - multidisciplinarity, the necessity of a geological educational background, long term time frames, etc.- also the fact that the CCS community is of recent formation, can explain the difficult task of dissemination, since no common representations have been developed yet and even among the experts there is a great need of exchange of information on the various aspects of the technology. Again, it is not just gathering information, but rather providing opportunities for processing it and unveiling its meaning in terms that can be meaningful both for specialized and non-specialized stakeholders. The project has shown that the DAA work can be effective in empowering the researchers in finding congenial ways to achieve the communication goal.

4. The importance of information in supporting the psycho-social processes towards sustainability appears in itself quite limited. If we consider the work with the researchers we can see that the preparation of meaningful information to be disseminated is subsequent to the empowerment of researchers, and comes from sharing and discussion. In the same way, in the school, the information could be better examined and listened to when a positive and trusting environment had been created. Information is an essential part of the process but maybe we need to remind ourselves that information undergoes a continual process of transformation while it is being exchanged and more often than not, this process is far more important than the content itself.

5. The application of the DAA in the school has proven to be a heuristic tool, not only for research goals but potentially for educational goals too; although this was not the primary focus of the work, it is true that the role of the educational system cannot be underestimated in the effort towards sustainability. As Bangay states: "If the role of 
education is to help learners of all ages to develop the knowledge, skills and capacities which enable them to think critically, to solve problems, and to address uncertainty, then the focus of climate change interventions should not simply be on new inputs/ content (although these are also necessary), but also on more holistic ways of addressing climate change through high quality teaching and learning." (Bangay \& Blum, 2010, p.9). Our research confirms the importance of placing new information in an appropriate context of high human quality.

6. It clearly appears that the processes implied in the adoption of a new technology do not concern just the examined technology. They involve a number of other technically related content as well as wider social and personal processes and perspectives. This needs to be taken in account when planning communication activities which will also inevitably communicate what is not explicitly said, to ensure that what is or might be meaningful to people is not left out. A good and probably unique example of the public engaging in activities on energy issues that addresses this aspect, comes from the work carried on in Australia by Peta Ashworth and colleagues (Ashworth et al., 2009a). The framework they designed to support a large group process met, in many respects, both the need for appropriate environments for sharing and the need to contribute to solutions that emerge from research.

In conclusion, if we want a "more sustainable" energy system we need "more sustainable" settings for learning and working; settings that increase the possibilities for people to explore and discover their potential, to submit their contribution at all levels, towards solving energy issues. New settings are also needed in the context of social research to improve our capacity to support our society's change and transformation towards common goals. The approach we have experimented is proposed as a form of a new "hybrid" mode of knowledge production, which tries to be more functional to the need of interaction-based knowledge and hopes to give support for counteracting the "hubris" intrinsic in many of our technological problems (Hard \& Jamison, 2005). We would like to point out that there is something special each one of us can contribute with our thoughts and our feelings and that we need to include them in science for the benefit of all: "New ways of thinking and new ways of looking at things are desperately needed today. Children who have had the opportunity to think for themselves, to discover and explore the world at their own pace may grow up to be adults who are able to find new insights into old problems"(Layne, 2000). As it is shown by the work in the school, the potential for Achievement needs to be liberated...

\section{Acknowledgements}

The present work was conducted within the framework of $\mathrm{CO}_{2} \mathrm{GeoNet}$ European Network of Excellence for the Geological Storage of CO2, Project no. SES6-CT-2004-502816. Funding from the EC is gratefully acknowledged.

The author would like to thank the research community of $\mathrm{CO}_{2} \mathrm{GeoNet}$ Network of Excellence: a special thank to the scientists who accepted the challenge of confrontation and in particular to Salvatore Lombardi, Isabelle Czernichowski, Nick Riley and Sergio Persoglia.

Thank you to the teachers and the children of the Roman primary schools Mazzini, Manzoni and XX Settembre for their enthusiastic participation and collaboration: we learned a lot from you. 
Thank you to Francesco Zarlenga, Manuela Errante, Anna Baccani, Aldo Annunziatellis, Monia Coltella, Jonathan Anderlucci, Laura Antinucci, Stan Beaubien, Giancarlo Ciotoli, your contribute has been very much appreciated.

\section{References}

Ashworth, P., Pisarski, A. \& Littleboy, A. (2006). Social and Economic Integration Report: Understanding and Incorporating Stakeholder Perspectives to Low Emission Technologies in Queensland, Centre for Low Emission Technology.

Ashworth, P., Carr-Cornish, S., Boughen, N. \& Thambimuthu, K. (2009a). Engaging the public on carbon dioxide capture and storage: Does a large group process work?, Proceedings of the 9th International Conference on Greenhouse Gas Control Technologies (GHGT-9), Energy Procedia, Vol. 1(No.1), Washington DC, USA, pp. 4765-4773.

Ashworth P., Boughen, N., Mayhew, M. \& Millar, F. (2009b). An integrated roadmap of communication activities around carbon capture and storage in Australia and beyond, Proceedings of the 9th International Conference on Greenhouse Gas Control Technologies (GHGT-9), Energy Procedia, Vol. 1(No. 1), Washington DC, USA, pp. 4749-4756.

Atkinson, J. W., Heyns, R. W. \& Veroff, J. (1954). The effect of experimental arousal of the affiliation motive on thematic apperception, Journal of abnormal and social psychology, Vol.49(No.3): 405-410.

Bangay, C. \& Blum, N. (2010). Education responses to climate change and quality: Two parts of the same agenda?, International Journal of Educational Development, Vol. 30(No.4): 359-368.

Carli, R. (1972). Fenomenologia dell'adattamento sociale, in L. Ancona (ed.), Nuove questioni di psicologia, La Scuola, Brescia, pp.51-72.

Carli, R. (1987). L'analisi della domanda, Rivista di Psicologia Clinica 1:38-53.

Carli, R. \& Paniccia, R.M. (2003). Analisi della domanda. Teoria e intervento in psicologia clinica, Il Mulino, Bologna.

Carli, R. \& Paniccia, R.M. (1981). Psicosociologia delle organizzazioni e delle istituzioni, Il Mulino, Bologna.

Carli, R. \& Paniccia, R.M. (2002). L'analisi emozionale del testo. Franco Angeli, Milano.

Czernichowski-Lauriol, I., Arts, R., Durand, D., Durucan, S., Johannessen,P., May, F., Olivier, M.-L., Persoglia, S., Riley, N., Sohrabi, M., Stokka, S., Vercelli, S. \& VizikaKavvadias, O. (2009). CO2GeoNet, the unique role of the European scientific body on CO2 geological storage, Proceedings of the 9th International Conference on Greenhouse Gas Control Technologies (GHGT-9), Energy Procedia, Vol.1(No. 1), Washington DC, USA, , pp. 2043-2050.

De Best-Waldhober, M., Daamen, D. \& Faaij, A. (2009). Informed and uninformed public opinions on $\mathrm{CO} 2$ capture and storage technologies in the Netherlands, International Journal of Greenhouse Gas Control, Vol. 3(No. 3): 322-332.

Desbararts, J., Upham, P., Riesch, H., Reiner, D., Brunsting, S., Best-Waldhober, M. de, Duetschke, E., Oltra, C., Sala, R. \& McLachlan, C. (2010), Review of the public participation practices for cCs and non-ccs projects in europe. Near C02 project Work Package1.2 http://www.communicationnearco2.eu/fileadmin/communicationnearco2/user/ docs/WP1.2_Final_report.pdf

DOE-NETL (2009). Public outreach and education for carbon storage projects. (DOE/NETL2009/1391).http://www.netl.doe.gov/technologies/carbon_seq/refshelf/BPM_Pu blicOutreach.pdf 
Eurobarometer (2006). Attitudes towards energy, Special Eurobarometer 247/Wave 64.2 TNS Opinion and Social.

http://www.managenergy.net/download/ebs_247_en.pdf

Fischedick, M., Pietzner, K., Supersberger, N., Esken, A., Kuckshinrichs, W., Zapp, P., Lin[ss]en, J., Schumann, D., Radgen, P., Cremer, C., Gruber, E., Schnepf, N., Roser, A. \& Idrissova, F. (2009). Stakeholder acceptance of carbon capture and storage in Germany, Proceedings of the 9th International Conference on Greenhouse Gas Control Technologies (GHGT-9), Energy Procedia, Vol. 1(No. 1), Washington DC, USA, pp. 4783-4787.

Flynn, R. \& Bellaby eds. (2007). Risk and the public acceptance of new technologies, Palgrave Macmillan, New York.

Ha-Duong, M., Nadaï, A. \& Campos, A.S. (2009). A survey on the public perception of CCS in France, International Journal of Greenhouse Gas Control, Vol.3(No.5): 633-640.

Hard, M. \& Jamison, A. (2005). Hubris and hybrids : a cultural history of technology and science, Routledge, New York.

Heiskanen, E., Hodson, M., Raven, R. Feenstra, Y., Alcantud, A., Bauknecht, D., Brohmann, B., Fritsche, U., Fucsko, J., Jolivet, E., Maack, M., Mourik, R.M., Onsizk-Poplawska, A., Poti, B.M. \& Schaefer, B. (2007), Factors influencing the societal acceptance of new energy technologies: metaanalysis of recent European projects, Work Package 2 report of the Create Acceptance Project, FP6-2004-Energy-3, SUSTDEV-1.2.8. http: //www.createacceptance.net/fileadmin/createacceptance/user/docs/E07058.pdf.

IEAGHG, (2008). Carbon Capture and Storage. http://www.ieaghg.org/docs/general _publications/GHGT9\%20Reports\%20CD.pdf.

IPCC, (2005). IPCC special report on Carbon Dioxide Capture and Storage. Prepared by working group III of the Intergovernmental Panel on Climate Change. Cambridge University Press, Cambridge, United Kingdom and New York, NY, USA.

Jodelet, D. (1992). Le rappresentazioni sociali: un campo in espansione, in D. Jodelet (ed.), Le rappresentazioni sociali, Liguori, Napoli, pp.43-76.

Johnsson, F., Reiner, D., Itaoka, K. \& Herzog, H. (2010). Stakeholder attitudes on Carbon Capture and Storage--An international comparison, International Journal of Greenhouse Gas Control, Vol.4(No.2): pp. 410-418.

Layne, M. (2000). Learning at home: mother's guide to homeschooling, Sea Change Publications, Victoria.

Malone, E. L., Bradbury, J.A. \& Dooley, J.J. (2009). Keeping CCS stakeholder involvement in perspective, Proceedings of the 9th International Conference on Greenhouse Gas Control Technologies (GHGT-9), Energy Procedia, Vol. 1(No. 1), Washington DC, USA, pp. 4789-4794.

Malone, E.L., Dooley, J.J. \& Bradbury, J.A. (2010). Moving from misinformation derived from public attitude surveys on carbon dioxide capture and storage towards realistic stakeholder involvement, International Journal of Greenhouse Gas Control, Vol.4(No.2): 419-425.

Matte Blanco, I. (1981). L' inconscio come insiemi infiniti : Saggio sulla bi-logica. Einaudi, Torino.

McClelland D. C. (1987). Human Motivation. Cambridge University Press, London.

Moscovici, S. (1961,1976). La psychanalyse : son image et son public, Puf, Paris.

Orange, D.M., Atwood, G.E. \& Stolorow, R.D. (1997). Working intersubjectively: Contextualism in psaychoanalytic practice. Analytic Press, Hillsdale.

Reiner, D., Curry, T., de Figueredo, M., Herzog, H., Ansolabehere, S., Itaoka, K., Akai, M., Johnsson, F. \& Odenberger, M. (2006). An international comparison of public 
attitudes towards carbon capture and storage technologies, Proceedings of GHGT-8, 8th International Conference on Greenhouse Gas Control Technologies, Trondheim, Norway.

Reiner, D.M. (2008). A looming rhetorical gap: a survey of public communications activities for carbon dioxide capture and storage technologies, Electricity Policy Research Group Working Papers, No.0801, University of Cambridge, Cambridge. http://www.eprg.group.cam.ac.uk/wp-content/uploads/2008/11/eprg08012.pdf.

Shackley, S., Waterman, H., Godfroij, P., Reiner, D., Anderson, J., Draxlbauer, K. \& Flach, T. (2007). Stakeholder perceptions of CO2 capture and storage in Europe: Results froma survey, Energy Policy, Vol.35(No.10): 5091-5108.

Shackley, S., Reiner, D., Upham, P., de Coninck, H., Sigurthorsson, G. \& Anderson, J. (2009). The acceptability of CO2 capture and storage (CCS) in Europe: An assessment of the key determining factors: Part 2. The social acceptability of CCS and the wider impacts and repercussions of its implementation, International Journal of Greenhouse Gas Control, Vol. 3(No. 3): 344-356.

Shackley, S. \& Evar, B. (2009). Public Understanding, Engagement and Communication Efforts on CCS: A Review for the IEA CCS Roadmap, IEA, Paris.

Stangeland, A. (2007). A model for the CO2 capture potential, International Journal of Greenhouse Gas Control, Vol.1(No.4): 418-429.

Stephens, J.C., Bielicki, J. \& Rand, G.M. (2009). Learning about carbon capture and storage: Changing stakeholder perceptions with expert information, Proceedings of the 9th International Conference on Greenhouse Gas Control Technologies (GHGT-9), Energy Procedia, Vol.1(No.1), Washington DC, USA, pp. 4655-4663.

Stolorow, R.D., Atwood, G.E. \& Brandchaft, B. (1987). Psychoanalytic treatment: an intersubjective approach. Analytic Press, Hillsdale.

Stolorow, R.D. \& Atwood G.E. (1992). Context of being. The intersubjective foundation of psychological life. Analytic Press, Hillsdale.

ter Mors, E., Weenig, M. W. H., Ellemers, N., Daamen, D.D.L. \& de Best-Waldhober, M. (2009). Public information: On why and when multiple information sources are more effective than single information sources in communication about CCS, Proceedings of the 9th International Conference on Greenhouse Gas Control Technologies (GHGT-9), Energy Procedia, Vol.1(No.1), Washington DC, USA, pp. 4715-4718.

Terwel, B.W., Harinck, F., Ellemers, N., Daamen, D.D.L. \& De Best-Waldhober, M., (2009). Trust as predictor of public acceptance of CCS, Proceedings of the 9th International Conference on Greenhouse Gas Control Technologies (GHGT-9), Energy Procedia, Vol. 1(No.1), Washington DC, USA, pp. 4613-4616

Vercelli, S. \& Tambelli, R. (2005). Stakeholders acceptance and understanding of CO2 geological storage, in S.Lombardi, L.K.Altunina, S.E.Beaubien (ed.), Advances in the geological storage of carbon dioxide. International approaches to reduce anthropogenic greenhouse gas emissions, Kluwer Academic Publishers, New York: 345-358.

Vercelli, S. \& Lombardi, S. (2009) CCS as part of a global cultural development for environmentally sustainable energy production, Proceedings of the 9th International Conference on Greenhouse Gas Control Technologies (GHGT-9), Energy Procedia, Vol. 1(No.1), Washington DC, USA, pp. 4835-4841.

World Resources Institute (WRI), (2009). Guidelines for community engagement regarding carbon dioxide capture and storage (CCS) projects. August 2009 draft for stakeholder review. 


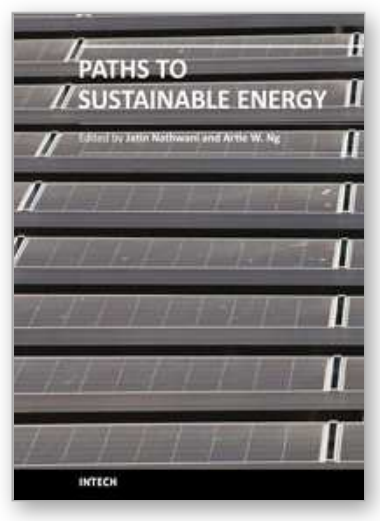

\author{
Paths to Sustainable Energy \\ Edited by Dr Artie $\mathrm{Ng}$
}

ISBN 978-953-307-401-6

Hard cover, 664 pages

Publisher InTech

Published online 30, November, 2010

Published in print edition November, 2010

The world's reliance on existing sources of energy and their associated detrimental impacts on the environment- whether related to poor air or water quality or scarcity, impacts on sensitive ecosystems and forests and land use - have been well documented and articulated over the last three decades. What is needed by the world is a set of credible energy solutions that would lead us to a balance between economic growth and a sustainable environment. This book provides an open platform to establish and share knowledge developed by scholars, scientists and engineers from all over the world about various viable paths to a future of sustainable energy. It has collected a number of intellectually stimulating articles that address issues ranging from public policy formulation to technological innovations for enhancing the development of sustainable energy systems. It will appeal to stakeholders seeking guidance to pursue the paths to sustainable energy.

\title{
How to reference
}

In order to correctly reference this scholarly work, feel free to copy and paste the following:

Samuela Vercelli (2010). Supporting Psychosocial Processes towards a Sustainable Energy System: the Case of CO2 Geological Storage, Paths to Sustainable Energy, Dr Artie Ng (Ed.), ISBN: 978-953-307-401-6, InTech, Available from: http://www.intechopen.com/books/paths-to-sustainable-energy/supporting-psychosocialprocesses-towards-a-sustainable-energy-system-the-case-of-co2-geological-sto

\section{INTECH}

open science | open minds

\author{
InTech Europe \\ University Campus STeP Ri \\ Slavka Krautzeka 83/A \\ 51000 Rijeka, Croatia \\ Phone: +385 (51) 770447 \\ Fax: +385 (51) 686166 \\ www.intechopen.com
}

\author{
InTech China \\ Unit 405, Office Block, Hotel Equatorial Shanghai \\ No.65, Yan An Road (West), Shanghai, 200040, China \\ 中国上海市延安西路65号上海国际贵都大饭店办公楼 405 单元 \\ Phone: +86-21-62489820 \\ Fax: +86-21-62489821
}


(C) 2010 The Author(s). Licensee IntechOpen. This chapter is distributed under the terms of the Creative Commons Attribution-NonCommercialShareAlike-3.0 License, which permits use, distribution and reproduction for non-commercial purposes, provided the original is properly cited and derivative works building on this content are distributed under the same license. 